\title{
Research on the Association of Consumption Structure With Industrial Structure and Economic Growth in Jinan City
}

\author{
Li Chen $^{1}$ \\ ${ }^{1}$ School of Economics, Shandong Women's University, Jinan, China \\ Correspondence: Li Chen, School of Economics, Shandong Women's University, Jinan 250300, Shandong, \\ China.E-mail: 806380657@qq.com
}

Received: January 1, 2022

Accepted: January 22, 2022

Online Published: January 26, 2022

doi:10.20849/abr.v7i1.988

URL: https://doi.org/10.20849/abr.v7i1.988

Project: Jinan City Philosophy and Social Science "Research on the correlation between urban and rural residents' consumption structure, industrial structure and economic growth in Jinan City", Project No. JNSK21C49.

\begin{abstract}
This paper empirically investigates the relationship between consumption structure, industrial structure and economic growth in Jinan City using vector autoregressive (VAR) model using 30 years of data from 1990-2020 in Jinan City. The results show that there is a two-way causal relationship between industrial structure and economic growth, and a two-way causal relationship between consumption structure and economic growth in Jinan City. Consumption structure can promote the optimization of industrial structure and further promote economic growth, while industrial structure does not play a proper role in promoting the regulation of consumption structure.
\end{abstract}

Keywords: consumption structure, industrial structure, economic growth, VAR model

\section{Introduction}

The relationship between consumption, industrial structure and economic growth has been a hot topic of research among scholars. With the rapid development of China's economy, the optimization of consumption structure can promote the upgrading of industrial structure, because compared with the total consumption, the consumption structure can better reflect the quality of consumption. In turn, the upgrading of industrial structure can further bring about the optimization of consumption structure, and the benign interaction between the two can further influence the transformation of economic growth mode, with the interaction and coordination among consumption structure, industrial structure and economic growth. 2020, the value added ratio of secondary and tertiary industries in China reached $37.8 \%$ and $54.5 \%$ respectively, and the ratio of tertiary industry has been maintained at over $50 \%$ since 2015. Jinan, as a provincial capital city, has a ratio of $34.8 \%$ and $61.6 \%$ of the added value of the secondary and tertiary industries respectively in 2020, and the ratio of the added value of the tertiary industry has been maintained above $60 \%$ from 2018, but compared with the ratio of the tertiary industry in Guangzhou (72.5\%) and Chengdu (65.72\%) and other provincial capital cities, there is still more room for the development of the tertiary industry in Jinan. How to further optimize the industrial structure and promote economic growth needs to be addressed. Therefore, it is of great practical significance to study the relationship between residents' consumption structure, industrial structure and economic growth for further optimization and upgrading of industrial structure and transformation of economic growth mode in Jinan city.

\section{Literature Review}

In 1825, after the outbreak of the first economic crisis in Britain, the Keynesian school introduced consumption into the system of economic theory, pointing out the relationship between income, consumption structure, industrial structure and economic growth, which brought a profound impact on the development of economic theory. At present, the research on the relationship between consumption structure, industrial structure and the economic growth is mainly focused on the following aspects. (1) Research on the correlation between consumer structure, industrial structure and economic growth. Kuznets (1941) argued that the increase of output per capita can increase the level of consumption and bring about the change of consumption structure, which in turn brings 
about the evolution of industrial structure and further promotes economic growth. Leontief (1951) analyzed the relationship between consumption structure and industrial structure, and used the input-output method to analyze the interaction between industrial structure and economic growth. Wu, Jin and Zhang, Hongwei (2010) considered the interaction between consumption structure and economic growth, and the three major mechanisms of their action are consumption demand, industrial structure and income distribution. Cha Daozhong and Ji Wenhui (2011) studied the relationship between residents' consumption structure, industrial structure and the economic growth using a vector autoregressive model, and concluded that there are urban-rural differences in the role of economic growth on consumption structure and urban-rural differences in residents' consumption structure on industrial structure upgrading. Zhang Cuiju and Zhang Zongyi (2016) studied the influence of urban and rural residents' consumption structure on industrial structure and economic growth using a spatial econometric model, and concluded that the three have significant spatial clustering characteristics. (2) The relationship between residential consumption structure and economic growth. Yin Shijie (2004) argues that the optimization of consumption structure can bring about an increase in consumption demand, which in turn promotes economic growth. Junko Doni (2003) analyzes the relationship between consumption structure and economic growth and argues that the degree of substitutability of goods affects industrial development, which in turn affects economic growth.(3) The relationship between industrial structure and consumption structure of residents. Wen Qixiang and Ran Jingfei (2005) measured and evaluated the harmony between consumption structure and industrial structure by constructing a harmoniousness analysis model. Tian Xuebin and Yan Zhen (2010) analyzed the relationship between consumption structure, residents' income and economic growth in Hebei Province by using VAR model. (4) The relationship between industrial structure and economic growth. Qian Chunhui et al. (2011) constructed an econometric model between industrial structure and economic growth, and analyzed the influence of industrial structure and economic growth on economic fluctuations. Liu Wei and Li Shaorong (2002) conducted an empirical analysis of the Chinese economy and concluded that improving the efficiency of the primary and secondary industries is necessary to promote long-term stable economic growth. Zhang eternal and Xue Jinli (2020) used VAR model to analyze the dynamic relationship between industrial transformation and upgrading and economic growth.

From the existing research areas, the studies mainly focus on the relationship between consumption structure and industrial structure, and the relationship between industrial structure and economic growth, etc. There is less literature that combines consumption structure, industrial structure and economic growth together, and there is no study that specifies the above relationship to Jinan city. This paper attempts to empirically investigate the dynamic influence relationship between consumption structure, industrial structure and economic growth in Jinan city from 1990 to 2020.

\section{Model Setting and Indicator Description}

\subsection{Model Setting}

Considering the interaction between the residential consumption structure, industrial structure and economic growth, this paper adopts a vector autoregressive (VAR) model using time series data from 1990 to 2020, and empirically analyzes the equilibrium relationship between the three using co-integration analysis, Granger causality test and variance decomposition from a long-term dynamic perspective.The VAR model was proposed by Christopher Sims ( Christopher Sims) in 1980, and since exogenous variables are not considered in this paper, the model is set as follows.

$$
Y_{t}=A_{1} Y_{t-1}+A_{2} Y_{t-2}+A_{3} Y_{t-3} \cdots+A_{p} Y_{t-p}+\varepsilon_{t}
$$

Among them, $\mathrm{Yt}=\left(\begin{array}{l}\operatorname{lngdp} \\ \operatorname{lncec} \\ \ln s t r\end{array}\right), \mathrm{A}_{1}, \mathrm{~A}_{2}, \ldots . \mathrm{A}_{\mathrm{P}}$ is the parameter matrix with estimation, $\mathrm{P}$ is the order of the autoregressive lag, and is the perturbation vector.

\subsection{Indicator Descriptions and Data Sources}

\subsubsection{Description of Indicators}

(1) Consumption structure. According to the existing statistical methods in China, the consumption expenditure of residents can be divided into eight categories, such as food, clothing, household equipment supplies and services. In this paper, we focus on the characteristics of urban residents' consumption structure and choose the urban residents' Engel's coefficient (CEC), which is the ratio of urban residents' food consumption expenditure to 
total consumption expenditure, as the proxy variable of consumption structure.(2) Industrial structure. According to the rule of evolution of the three industries, the tertiary industry accounts for a higher proportion of the national economy and develops faster than the secondary industry, so the proportion of the tertiary industry to the secondary industry is selected as an indicator of the economic structure of Jinan City, which is recorded as str.(3) Economic growth. In order to exclude the influence of price factors, this paper converts GDP into real GDP at constant prices in 1978 by using the gross regional product index, which is expressed as gdp.

Since the logarization of the data does not affect the covariance of the original variables, and can eliminate the possible heteroskedasticity and make the data linear, the above variables are taken as logarithms in this paper and expressed as lncec, lnstr and lngdp, respectively.

\subsubsection{Data Sources}

The data used in this paper were obtained from the Jinan Statistical Yearbook in previous years, and the sample interval was 1990-2020, and all tests were done under Stata16 software.

\section{Empirical Tests}

\subsection{Smoothness Test of Variables}

In this paper, the ADF unit root test is used to test the smoothness of the series lngdp, lncec, lnstr and their first-order differences, and the results are shown in Table 1. According to the results of the ADF test, it can be seen that lngdp, lncec, and lnstr all have unit roots and are non-smooth series, while their first-order difference series are all smooth at the $1 \%$ level, that is, they are single integer series of order 1 .

Table 1. Tests for smoothness of variables

\begin{tabular}{rrrrrrr}
\hline & $\begin{array}{r}\text { Test } \\
\text { Statistic }\end{array}$ & $\begin{array}{r}\text { Test } \\
\text { Form }(\mathrm{c}, \mathrm{t}, \mathrm{p})\end{array}$ & $\begin{array}{c}\text { 1\%Critical } \\
\text { Value }\end{array}$ & $\begin{array}{c}5 \% \text { Critical } \\
\text { Value }\end{array}$ & 10\%Critical Value & Conclusion \\
\hline lngdp & 1.054 & $(\mathrm{c}, \mathrm{t}, 0)$ & -4.334 & -3.580 & -3.228 & Unstable \\
lncec & -1.985 & $(\mathrm{c}, \mathrm{t}, 0)$ & -4.334 & -3.580 & -3.228 & Unstable \\
lnstr3 & -2.997 & $(\mathrm{c}, \mathrm{t}, 0)$ & -4.334 & -3.580 & -3.228 & Unstable \\
dlngdp & -4.428 & $(\mathrm{c}, 0,0)$ & -4.343 & -3.584 & -3.230 & Stable*** \\
dlncec & -6.160 & $(\mathrm{c}, 0,0)$ & -4.343 & -3.584 & -3.230 & Stable*** \\
dlnstr3 & -4.533 & $(\mathrm{c}, 0,0)$ & -4.343 & -3.584 & -3.230 & Stable*** \\
\hline
\end{tabular}

Note: $* * *, * * *$ denote $1 \%, 5 \%$, and $10 \%$ significance levels, respectively. dlngdp, dlncec, and dlnstr are the first-order differences of lngdp, lncec, and lnstr, respectively.

\subsection{Selection of Lag Order and Stability Test}

When performing VAR modeling, the lag order of the variables is first determined. In this paper, five methods, LR, FPE, AIC, HQIC, and SBIC, were used simultaneously to estimate the order of the VAR system according to the information criterion, and the results are shown in Table 2. It can be seen from the table that the optimal lag order is 4, so the VAR(4) model is established.

Table 2. Lag orders of the VAR model

\begin{tabular}{rrrrrrrrr}
\hline lag & LL & LR & df & p & FPE & AIC & HQIC & SBIC \\
\hline 0 & 53.6813 & & & & $4.7 \mathrm{e}-06$ & -3.75417 & -3.71135 & -3.61018 \\
1 & 186.019 & 264.68 & 9 & 0.000 & $5.1 \mathrm{e}-10$ & -12.8903 & -12.7191 & -12.3144 \\
2 & 200.036 & 28.032 & 9 & 0.001 & $3.6 \mathrm{e}-10$ & -13.2619 & -12.254 & -12.254 \\
3 & 216.395 & 32.72 & 9 & 0.000 & $2.3 \mathrm{e}-10$ & -13.8071 & $-12.3673^{*}$ & $-12.3673^{*}$ \\
4 & 229.435 & $26.079 *$ & 9 & 0.002 & $1.9 \mathrm{e}-10^{*}$ & $-14.1063^{*}$ & $-13.5497^{*}$ & -12.2345 \\
\hline
\end{tabular}


The VAR (4) model is tested for stability on the basis of the series smoothness test, and the results are shown in Figure 1. All eigenvalues are within the unit garden, so the model is stable.

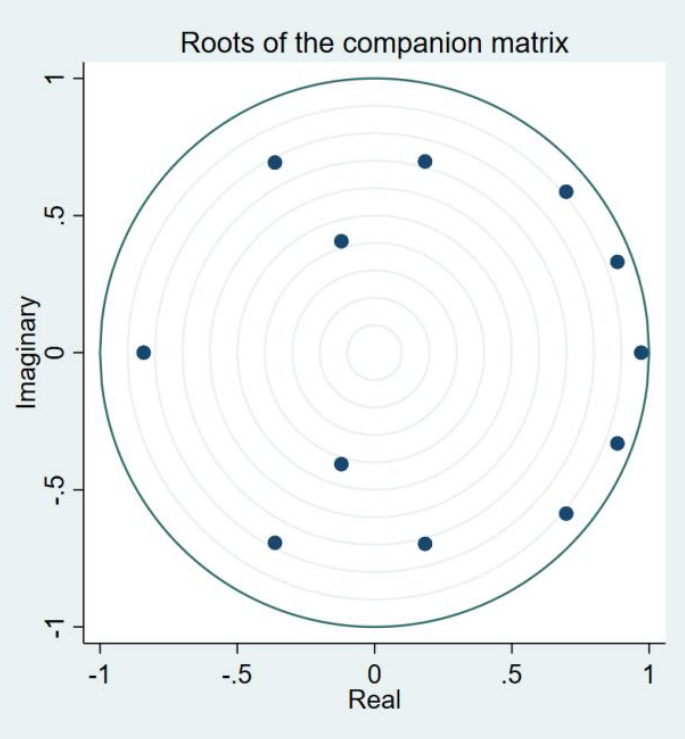

Figure 1. Discriminant diagram of VAR system stability

\subsection{Co-integration Test and Build VEC Model}

The original series lngdp, lncec, lnstr3 of the VAR model has been determined earlier to be non-smooth and a first order single integer series, the following further tests whether there is a cointegration relationship between the series. The Johansen cointegration test is used to determine whether there is a long-term stable relationship between the industrial structure, residential consumption structure and economic growth in Jinan, and the test results are shown in Table 3. it can be seen that at the 5\% level, there is at least one cointegration relationship among lngdp, lncec and lnstr3, i.e., there is a long-term equilibrium relationship among the three variables, and the following cointegration equation is obtained.

$$
\text { lncec }=23.31-4.66 \operatorname{lngdp}+5.76 \ln s t r 3
$$

It can be seen that there is an inverse economic relationship between residents' consumption structure and economic growth. According to the definition of consumption structure in this paper, it can be seen that for every $1 \%$ increase in economic growth, the Engel coefficient of urban residents decreases by $4.66 \%$, i.e., economic growth promotes the optimization of consumption structure. Economic growth brings about an increase in residents' disposable income, which makes residents increase their consumption of non-food products on the basis of meeting their basic living needs, i.e., economic growth improves the consumption structure by increasing residents' consumption capacity. The industrial structure is not the reason to promote the optimization of residents' consumption structure, but rather inhibits the optimization of residents' consumption structure to a certain extent, which may be related to the unreasonable internal structure of the tertiary industry in Jinan. The proportion of wholesale, retail and catering industries in Jinan's tertiary industry is much higher than that of services such as education and culture. The development of the tertiary industry does not provide more consumer goods to residents, and thus does not play a supporting role in the optimization of residents' consumption structure. 


\subsection{Causality Test}

Table 3. Johansen co-integration test

\begin{tabular}{rrrrrr}
\hline $\begin{array}{r}\text { Maximum } \\
\text { rank }\end{array}$ & parms & LL & eigenvalue & Trace statistic & $\begin{array}{r}5 \% \text { critical } \\
\text { value }\end{array}$ \\
\hline 0 & 33 & 207.81483 & & 50.9846 & 34.55 \\
1 & 38 & 226.38499 & 0.74730 & $13.8443^{*}$ & 18.17 \\
2 & 41 & 231.76827 & 0.32885 & 3.0778 & 3.74 \\
3 & 42 & 233.30716 & 0.10773 & & \\
\hline
\end{tabular}

The co-integration test shows that there is a long-term equilibrium economic relationship between lngdp, lncec and lnstr3, but whether this relationship is causal or not needs further Granger causality test, the results are shown in Table 4. it can be seen that the current industrial structure of Jinan City does not play a proper role in the optimization of residents' consumption structure, which is related to the unreasonable internal structure of the tertiary industry, while The consumption structure is conducive to the optimization of the industrial structure; the industrial structure and economic growth are causally related, the optimization of the industrial structure can promote economic growth, and the economic growth can further promote the adjustment of the industrial structure; the consumption structure and economic growth have a two-way causal relationship, the economic growth can promote the optimization of the consumption structure by improving the consumption ability of residents, and the optimization of the consumption structure can further drive the economic growth.

Table 4. Granger causality test

\begin{tabular}{clccc}
\hline ho & Chi2 & Df & prob & Conclusion \\
\hline Lncec is not lngdp's Granger cause & 14.206 & 4 & 0.007 & Rejection \\
Lngdp is not lncec's Granger cause & 15.135 & 4 & 0.004 & Rejection \\
Lnstr3 is not lngdp's Granger cause & 24.124 & 4 & 0.000 & Rejection \\
Lngdp is not lnstr3's Granger cause & 83.556 & 4 & 0.000 & Rejection \\
$\quad$ lnstr3 is not lncec's Granger cause & 6.9153 & 4 & 0.140 & Rejection \\
Lncec is not lnstr3's Granger cause & 39.142 & 4 & 0.000 & Rejection \\
\hline
\end{tabular}

\subsection{Variance Decomposition}

The variance decomposition evaluates the importance of different structural shocks by looking at the contribution of each structural shock to the changes in the endogenous variables. The results of the variance decomposition of the endogenous variables are shown in Table 5. from Table 5, it can be seen that economic growth has a large impact on both residential consumption structure and industrial structure, and this impact roughly tends to increase and reaches $28.7 \%$ and $41.2 \%$, respectively, in period 10 . The influence of residents' consumption structure on economic growth and industrial structure reaches $16 \%$ and $39.1 \%$ respectively in the 10th period, and this influence has a tendency to expand. The influence of industrial structure on residents' consumption structure is small, which may be related to the unreasonable internal structure of tertiary industry in Jinan. 
Table 5. Variance decomposition of lncec, lngdp, lnstr3

\begin{tabular}{rllllll}
\hline & \multicolumn{2}{c}{$\begin{array}{c}\text { Incec's variance } \\
\text { decomposition }\end{array}$} & \multicolumn{2}{c}{$\begin{array}{c}\text { Ingdp's variance } \\
\text { decomposition }\end{array}$} & \multicolumn{2}{c}{$\begin{array}{c}\text { Instr3's variance } \\
\text { decomposition }\end{array}$} \\
\hline step & lngdp & lnstr3 & lncec & lnstr3 & lncec & lngdp \\
1 & .000138 & 0 & 0 & 0 & .162063 & .009255 \\
2 & .041313 & .01387 & .001907 & .099595 & .182471 & .196483 \\
3 & .08898 & .011568 & .008574 & .094042 & .364684 & .294172 \\
4 & .221225 & .012578 & .019262 & .071604 & .34551 & .382196 \\
5 & .268824 & .012205 & .013962 & .068275 & .342921 & .404229 \\
6 & .300756 & .011959 & .016338 & .065713 & .323813 & .393768 \\
7 & .305795 & .014915 & .030889 & .060626 & .338142 & .390078 \\
8 & .298124 & .017667 & .061136 & .061054 & .387704 & .376074 \\
9 & .29241 & .021095 & .10909 & .062178 & .395706 & .392578 \\
10 & $\operatorname{lngdp}$ & .020641 & .160016 & .062584 & .390643 & .411905 \\
\hline
\end{tabular}

\section{Conclusions and Policy Recommendations}

This paper analyzes the relationship between the residential consumption structure, industrial structure and economic growth in Jinan using VAR model. The results of the study show that (1) there is a long-term equilibrium relationship between the residential consumption structure, industrial structure and economic growth in Jinan. (2) The industrial structure and economic growth in Jinan are causally related to each other, and the upgrading of industrial structure can promote economic growth, and economic growth can further survive the upgrading of industrial structure. (3) Consumption structure and economic growth have a two-way causal relationship, economic growth can promote the optimization of consumption structure by improving residents' consumption ability, and the optimization of consumption structure can further drive economic growth. (4) Jinan's industrial structure does not play a role in the optimization of residents' consumption structure, which is related to the unreasonable internal structure of the tertiary industry, while the consumption structure is conducive to the optimization of industrial structure.

In order to expand domestic demand, stimulate the economy, optimize the consumption structure and industrial structure, and achieve the benign and coordinated development of the three, the following policy suggestions are proposed in response to the above findings. First, optimize the internal structure of the tertiary industry. Vigorously develop modern service industries such as education and culture as well as new high-tech industries to cultivate new consumption growth points, which in turn will lead to the optimization of consumption structure. Secondly, improve the income distribution structure. The relevant departments of Jinan government should formulate a reasonable income distribution system, narrow the income gap, raise the income level of residents, promote consumption and improve the consumption structure, which in turn will bring about the optimization of industrial structure and stable economic growth. Third, promote scientific and technological progress. Jinan City should vigorously develop high-tech industries, promote scientific and technological innovation, realize the transformation of economic development mode, and drive sustained and stable economic growth, which will in turn bring about the optimization of industrial structure and consumption structure.

\section{References}

Cha, D. C., \& Ji, W. H. (2011). Rural Residents, Industrial Structure and Economic Growth-Empirical Analysis Based on VAR Mode. On Economic Problems, (7), 19-22. https://doi.org/10.16011/j.cnki.jjwt.2011.07.009

Doi, J. (2003). Consumption Structure and the Pattern of Economic Growth. Seoul Journal of Economics, 16(3), 343-362.

Gan, C. H., Zheng, R. G., \& Yu, R. G. (2011). An Empirical Study on the Effects of Industrial Structure on Economic Growth and Fluctuations in China. Economic Research Journal, 46(5), 4-16, 31.

Kuznets, S. (1941). National Income, 1919-1938. NBER, 1-30.

Leontief. (1951). The structure of American economy. New York: Oxford University Press. 
Liu, W., \& Li, S. R. (2002). Industrial Structure and Economic Growth. China Industrial Economy. https://doi.org/10.19581/j.cnki.ciejournal.2002.05.002

Wen, Q. X., \& Ran, J. F. (2005). The Differences Analyses of Strategic Status and Financial Status of Different Assets. China Industrial Economics, (8), 14-19, 104. https://doi.org/10.19581/j.cnki.ciejournal.2005.08.002

Zhang, C. J., \& Zhang, Z. Y. (2016). Research on the Spatial Effect of Consumption Structure on Industrial Structure and Economic Growth: Based on Spatial Panel Model. Statistics \& Information Forum, 31(8), $46-52$.

Zhang, Y. H., \& Xue, J. L. (2020). Research on the dynamic relationship between industrial transformation and upgrading and economic growth. Statistics \& Decision, 36(6), 96-99. https://doi.org/10.13546/j.cnki.tjyjc.2020.06.021

\section{Copyrights}

Copyright for this article is retained by the author(s), with first publication rights granted to the journal.

This is an open-access article distributed under the terms and conditions of the Creative Commons Attribution license (http://creativecommons.org/licenses/by/4.0/). 